\title{
Analysis of sea conditions for manned submersible operation in Southwest Indian Ocean
}

\author{
Qin Shengjie ${ }^{1,2}$, Yang Lei ${ }^{1}$, Liu Xiaohui ${ }^{1}$, Tang Miao ${ }^{1}$ and Zhan Hongxu ${ }^{1}$ \\ ${ }^{1}$ National deep sea Center, Qingdao, Shandong, China \\ ${ }^{2}$ Yellow Sea Fisheries Research Institute, Qingdao, Shandong, China
}

\begin{abstract}
The southwest Indian Ocean is an important area for deep-sea investigation and exploration. In this paper, the spatial distribution and temporal variation characteristics of wave elements in the sea area were analyzed by using the high resolution reanalysis data (ERA) from the European Center, the optimal path set of tropical cyclones provided by the Joint Warning Center (JTWC) and the global ocean circulation model (OFES). The results show that the monthly mean effective wave height in the southwest Indian Ocean is relatively large, ranging from $3.5 \mathrm{~m}$ to $5.5 \mathrm{~m}$. the wave season is relatively stable, with the highest mean wave height in winter and the lowest mean wave height in summer; The frequency of tropical cyclones is higher in summer and autumn and lower in winter; The most suitable operation time of manned submersible in the southwest Indian Ocean is from November to march of the next year, and other time needs to select good sea conditions for operation.
\end{abstract}

\section{Introduction}

The Southwest Indian Ridge is a hot area of earth science research, which is the boundary between the Antarctic plate and the African plate. It is an ideal place for understanding the lithospheric growth model of the ultra-slow spreading oceanic ridge, improving the mantle upwelling model and hydrothermal circulation mechanism ${ }^{[1]}$. In 2011, China signed a contract with the International Seabed Authority (ISA) for the middle part of the southwest Indian ridge $\left(49^{\circ}-53^{\circ} \mathrm{S}\right)$ The international seabed polymetallic sulfide exploration contract covers an area of about 10000 square kilometers. Up to now, about one third of the ocean scientific research voyages organized by China have been to the southwest Indian Ocean, and manned submersibles have been used for many times to carry out near bottom highprecision sampling and measurement, which is of great significance for the study of metallogenic mechanism, biodiversity, hydrothermal microbial life process and gene resource potential of polymetallic sulfide in ultra slow spreading ridge ${ }^{[2]}$.

Due to the frequent circumpolar cyclone frontal system and cold air activity in the southwest Indian Ocean, the westerly belt is stable all the year round. Affected by it, the strong wind area in the southwest Indian Ocean is located between $40 \mathrm{~s}$ and $60 \mathrm{~s}$ all the year round, with the average wind speed above grade 6 , and the sea condition is bad, which has a great impact on the marine survey operation. As "an important cornerstone of oceanographic research"[3], manned submersible is an important carrier equipment for human exploration of the ocean, which can carry scientists and engineers to carry out seabed scientific investigation and exploration operations under atmospheric pressure. Taking the Jiaolong manned submersible as an example, the manned submersible carries the supporting mother ship to the operation sea area. When the mother ship works on the water surface, it is greatly affected by wind, waves and currents. In the stage of deployment, recovery and surface floating, the submersible is greatly affected by waves and currents ${ }^{[4]}$, and its operating conditions are level 4 sea state deployment and level 5 sea state recovery ${ }^{[5]}$.

In order to ensure the safety of submarine operation at sea and improve the frequency and efficiency of submergence during the voyage, this paper uses the synoptic analysis method to collect and analyze the data products of marine environment, analyzes and summarizes the characteristics of wind, wave, current, extreme sea conditions and other elements in the southwest Indian Ocean, so as to provide auxiliary decision-making information for selecting a reasonable operation window of deep submersibles and ensuring the operation safety.

\section{Data and analysis methods}

In order to scientifically analyze the environment of the southwest Indian Ocean, the European center high resolution reanalysis data era is used in this paper Interim, JTWC, ofes and other data products. For wind and wave data, it is difficult to obtain continuous longtime historical observation data, so at present, researchers and business personnel at home and abroad will choose several types of reanalysis data to replace the

\footnotetext{
* Corresponding author: 865688567@qq.com
} 
observation data. After comparing some buoy wind data and reanalysis wind data, it is found that CCMP and European center high-resolution reanalysis data are the best. Because CCMP wind data only up to 2011, in order to select the latest 20 years data for climate background analysis, this paper finally selects European center highresolution reanalysis data era Interim (1979- present) has carried out relevant analysis. Wind elements include meridional wind and latitudinal wind with a resolution of $0.125^{\circ} * 0.125^{\circ}$. Wave elements include significant wave height and wave period with resolution of $0.125^{\circ} *$ $0.125^{\circ}$ 。

The best track set of tropical cyclones from 1990 to 2009 provided by JTWC is selected for the data of tropical cyclones, and the data is missing. The statistical results show that all the tropical cyclones affecting the southwest Indian Ocean in recent 20 years. In the aspect of tropical cyclone intensity statistics, the unified international classification standard is adopted.

In terms of analysis methods, this report mainly adopts the synoptic analysis method to carry out monthly analysis on the characteristics of wind field, wave field, tropical cyclone and surface flow field in the target sea area, and briefly analyzes the characteristics and causes combined with the main weather systems in the sea area.

\section{Data analysis and comparison}

\subsection{Monthly average sea wave condition for many years}

The geographical distribution map of wave height and period can more intuitively show the characteristics of wave and reflect the distribution of effective wave height in different sea areas. Therefore, according to $0.125^{\circ} * 0.125^{\circ}$. The significant wave height at each grid point is analyzed by monthly average. In order to understand the overall significant wave height of the sea area, the monthly regional average value of the significant wave height data is also calculated, so as to analyze the probability statistics of the occurrence frequency and spatial-temporal distribution characteristics of giant waves in the southwest Indian Ocean, and the following results are obtained: according to the analysis, the monthly average significant wave height and period geographical distribution of the sea area are shown in Fig. 1.

Affected by the steady westerly belt, the strong wind area of the southwest Indian Ocean is located in the westerly belt between $40 \mathrm{~s}$ and $60 \mathrm{~s}$, with an average wind speed of $11 \sim 12 \mathrm{~m} / \mathrm{s}$, and the strong wind area and wind speed are slightly affected by the month. Affected by the frequent cold air activities in winter, strong southeast wind was maintained in most of the sea areas between 0 30 s from June to September, with the average wind speed of $9 \sim 10 \mathrm{~m} / \mathrm{s}$.

The effective wave height and average wave period of each month are relatively stable compared with other sea areas due to the influence of the above weather system. The effective wave height of the westerlies in the whole year is larger, which is maintained at 3.5 $5.5 \mathrm{~m}$; The maximum of the westerlies in May August is $4.5 \sim 5.5 \mathrm{~m}$; The effective wave height of low latitude sea area is relatively small. In terms of average wave period, except for the average wave period of some sea areas east of the East African plateau is about $6 \sim 7$ seconds all year round, the average wave period of other sea areas is between $8 \sim 10$ seconds.
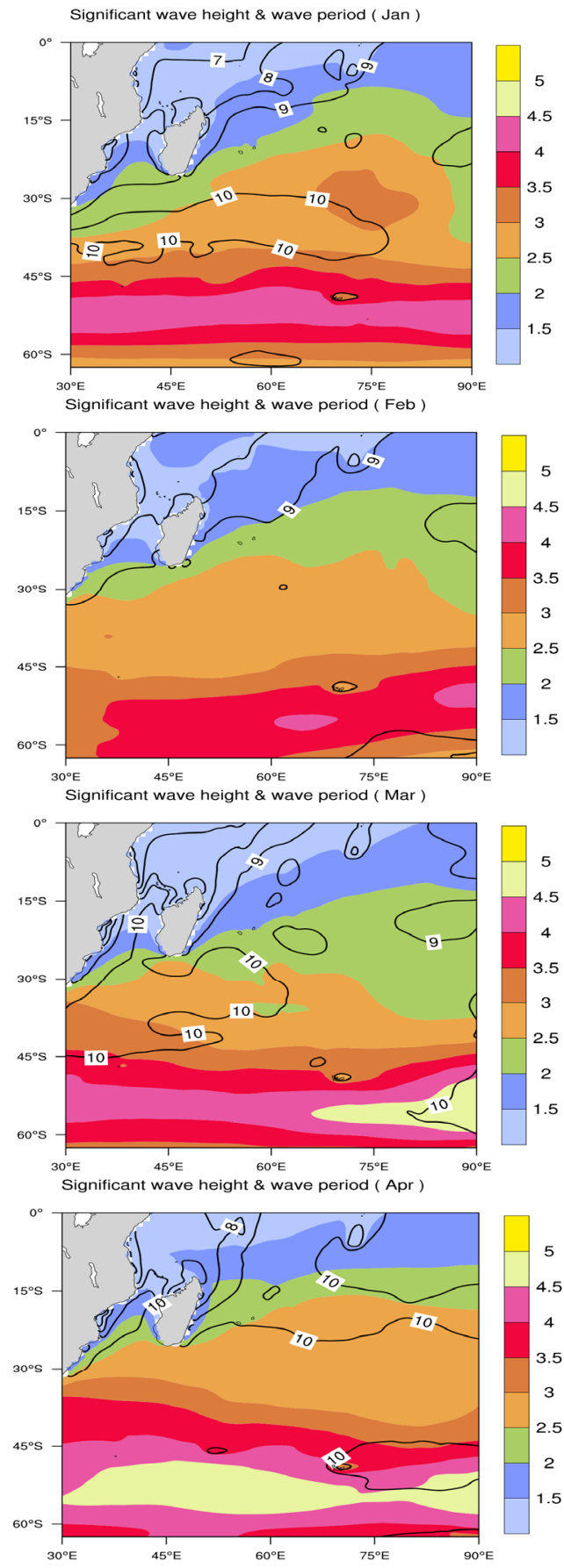

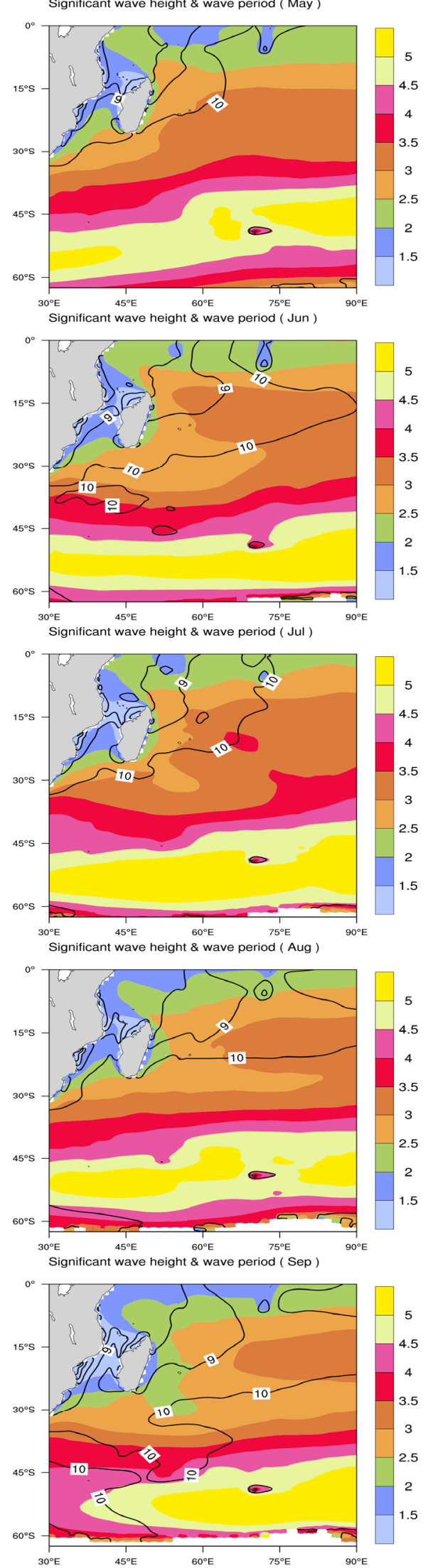

Significant wave height \& wave period ( Oct )

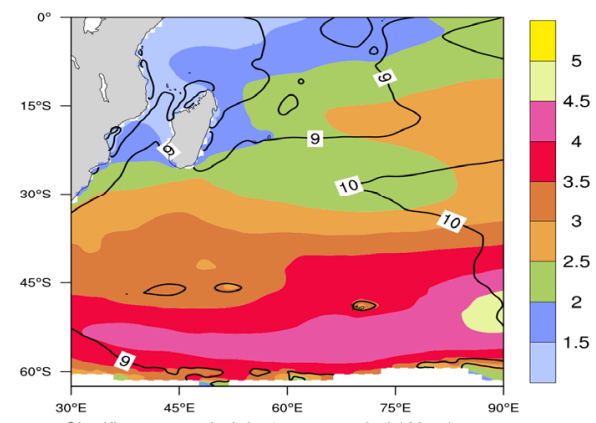

Significant wave height $\&$ wave period ( Nov)
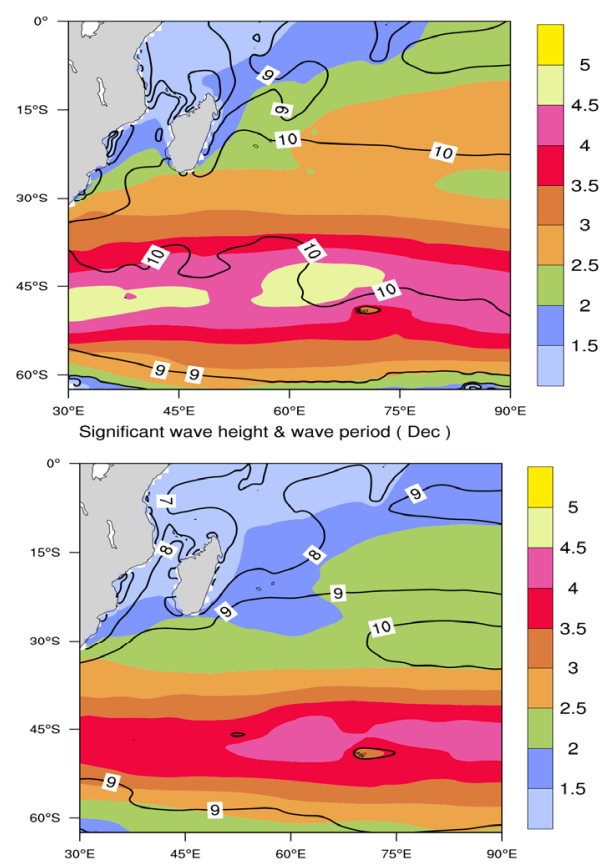

Fig. 1 Significant wave height and wave period field (January to December)

\subsection{Temporal and spatial distribution of huge waves}

There are two typhoon seasons in the southwest Indian Ocean every year, from January to April and October to December (due to the opposite seasons in the southern hemisphere and China, which is equivalent to summer and autumn in the southern hemisphere), tropical cyclones are affected in each month. The most influential months are January and February, with an average annual average of about 2.5. The months with the least influence are June August (Fig. 2).

1990-2009 SWI

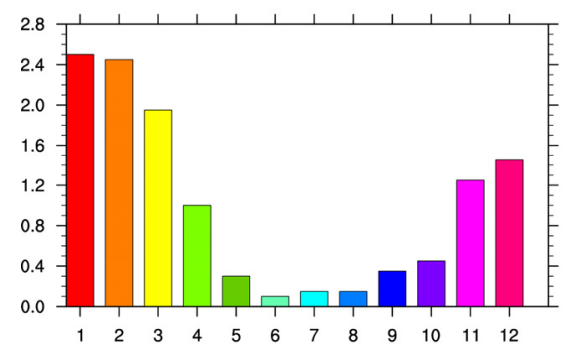

Fig. 2 Frequency of Tropical Cyclone Impact in each month 


\section{Safety analysis of offshore operation}

The design condition of Jiaolong manned submersible is to deploy under four sea conditions and recover under five sea conditions. In order to ensure the safety of submersible operation, this paper calculates the annual frequency of Level 4 and Level 5 sea conditions in the southwest Indian Ocean. As shown in Fig. 3 and Fig. 4

From November to February, the sea conditions were slightly better in the north sea area of $30 \mathrm{~S}$, with about 15 days exceeding class 4 sea conditions in each month, and less than 10 days exceeding class 4 sea conditions in the northwest sea area. From $30 \mathrm{~S}$ to $60 \mathrm{~S}$, it is the westerly sea area, and the sea state is poor all the year round. In November and February, the sea state is slightly better, but the number of days exceeding sea state level 4 in each month is also more than 27 days, and the number of days exceeding sea state level 5 is also more than 15 days. From May, the sea conditions in the whole area of the southwest Indian Ocean became worse and continued to October. The number of days exceeding level 4 sea conditions in each month was about 27 , and the area exceeding level 5 sea conditions was south of $15 \mathrm{~S}$, and the number of days was more than 12 .
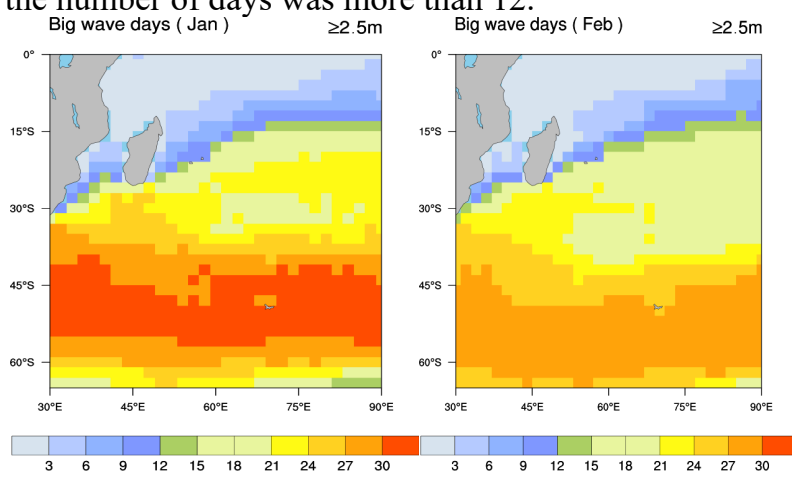

Big wave days ( Mar)

$22.5 \mathrm{~m}$ Big wave days ( Apr)

$22.5 \mathrm{~m}$
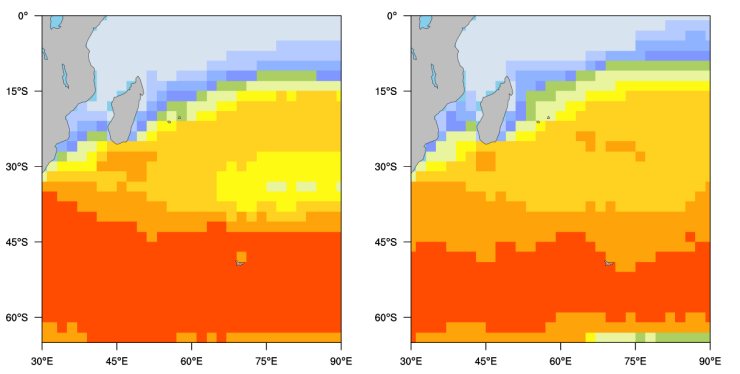

\begin{tabular}{llllllll|l|l|}
3 & 6 & 9 & 12 & 15 & 18 & 21 & 24 & 27 & 30
\end{tabular}

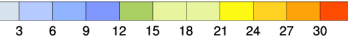

Big wave days ( May) Big wave days ( Jun )

$22.5 \mathrm{~m}$
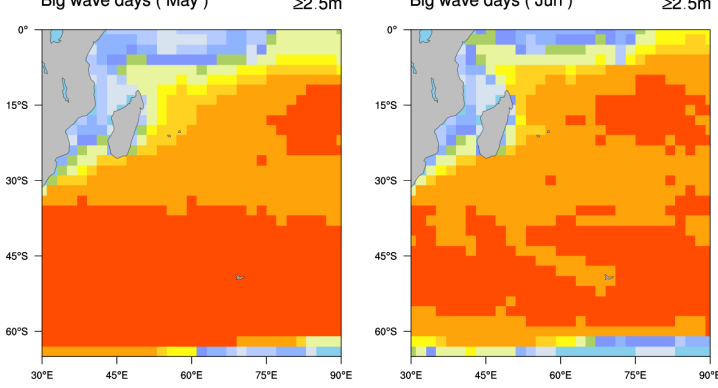

Big wave days ( Jul )
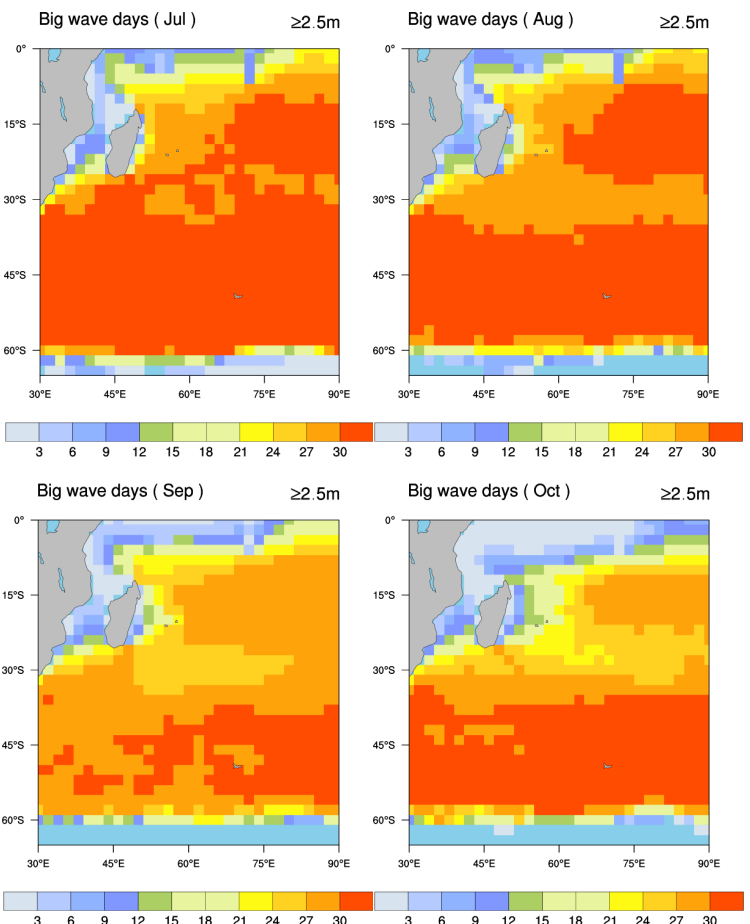

Big wave days ( Nov)

$22.5 \mathrm{~m}$

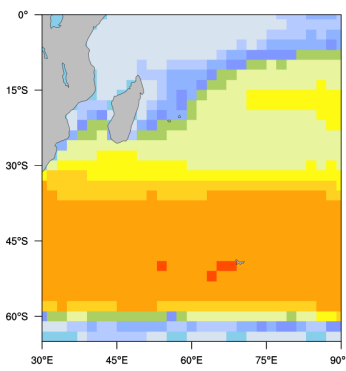

Big wave days ( $\mathrm{Dec}$ )

$22.5 \mathrm{~m}$
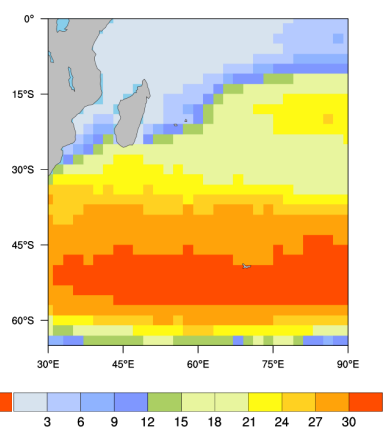

Fig. 3 Statistics of days exceeding grade 4 sea state
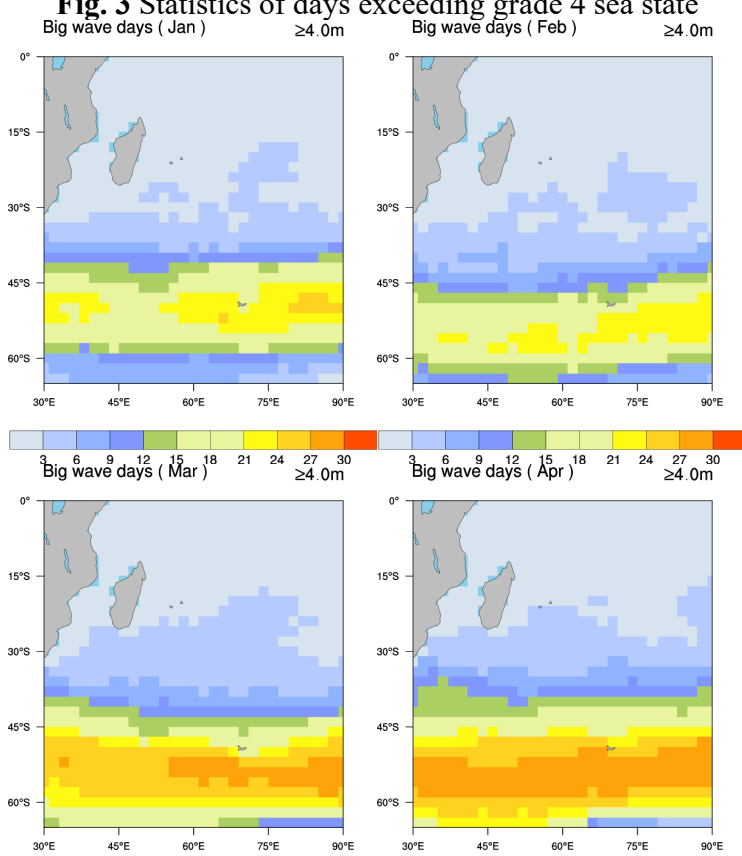

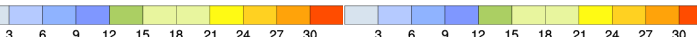



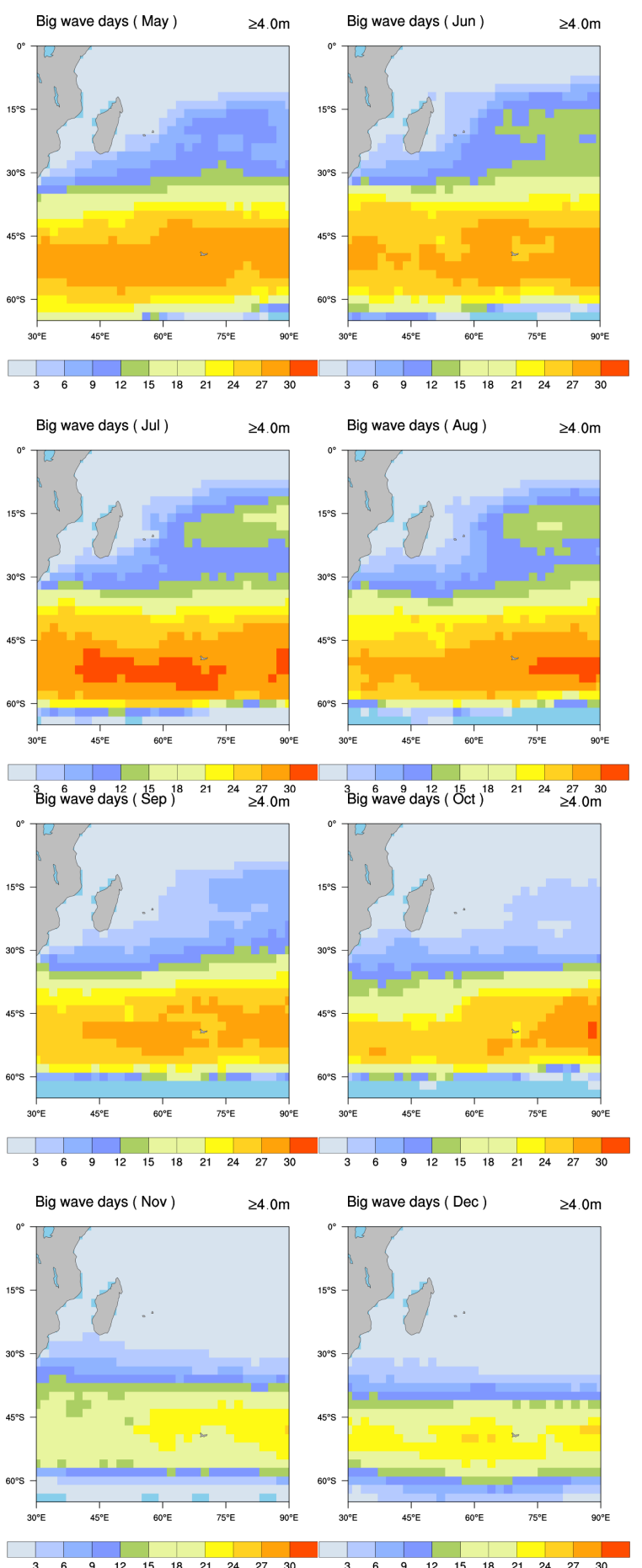

$3 \quad 6^{6}$
Fig. 4. Statistics of days exceeding grade

\section{Conclusion}

(1) In the southwest Indian Ocean, the effective wave height in the westerly zone is relatively high, with the effective wave height ranging from $3.5 \mathrm{~m}$ to $5.5 \mathrm{~m}$ and the period being from $6 \mathrm{~s}$ to $10 \mathrm{~s}$. The wave season is relatively stable, with the maximum mean wave height in winter and the minimum in summer.

(2) There are tropical cyclones in every month, with higher frequency in summer and autumn, and lower frequency in winter. In terms of intensity, the highest intensity tropical cyclone activity occurred from
February to April and from November to December, among which April accounted for the highest proportion.

(3) From November to February, the number of days exceeding class 4 sea state in each month in the sea area north of $30 \mathrm{~S}$ is about 15 days, and the number of days exceeding class 4 sea state in each month in the sea area northwest is less than 10 days. From $30 \mathrm{~S}$ to $60 \mathrm{~S}$, it is the westerly sea area, and the sea state is poor all the year round. In November and February, the sea state is slightly better, but the number of days exceeding sea state level 4 in each month is also more than 27 days, and the number of days exceeding sea state level 5 is also more than 15 days. From May, the sea conditions in the whole area of the southwest Indian Ocean became worse and continued until October.

(4) The most appropriate operation time for manned submersible in the southwest Indian Ocean is from November to March of the next year, and the sea conditions are poor at other times. If it is necessary to conduct operations, it is necessary to pay close attention to the weather changes and avoid operations under bad sea conditions.

\section{References}

1. Tao C.H, Li H.M, Jin X.B, et al. (2014) Submarine hydrothermal activity and sulfide exploration in the Southwest Indian Ridge. J. Chinese Science Bulletin, 59:1812-1822.

2. Yang W.F. (2017) Research on the metallogenesis of the Broken Bridge hydrothermal area in the middle ridge of the Southwest Indian Ocean. D. Zhejiang University.

3. Liu F, Cui W.C, Li X.Y. (2010) China' s first deepsea manned submersible-Jiaolong. J. Science China: Earth Sciences, 40: 1617-1620.

4. Qin S.J, Zhang Y, Ding Z.J et al. (2019) Statistics and analysis of structural defects of Jiaolong manned submersible. J. Ship and Ocean Engineering, 48: $140-142+147$.

5. Cui W.C. (2012) "Jiaolong" manned submersible key technology research and independent innovation. J. Ship and Ocean Engineering, 1: 1-8. 